\title{
Electroencephalographic and temporal correlates of snoring*
}

\author{
IRA B. ALBERT and NICHOLAS C. BALLAS \\ Old Dominion University, Norfolk, Va. 23508
}

Continuous sleep recordings were obtained for eight reliable snorers. Although most snoring occurred during Stage 2 sleep, it was found that the tendency to snore was not significantly different for the various sleep stages. However, the greatest amount of snoring occurred at the beginning of the night.

Snoring, which has been defined as "sounds made by vibrations in the soft palate and posterior faucial pillars during sleep [Robin, 1968]," is a very frequent problem in the general population. In fact, interest in this topic is so great that 168 antisnoring devices have been patented in the United States (Boulware, 1967). These devices include harnesses to keep the mouth shut and devices to keep a person off his back (Kleitman, 1963). On occasion, medical practitioners have injected sclerosing material into the soft palate and have employed exercises to strengthen various facial muscles (Shapiro, 1971). However, none of these treatments is reliable in reducing the incidence of snoring.

In one of the few experimental studies to analyze the variables which are correlated with snoring, Fischgold \& Schwartz (1961) attempted to correlate snoring with the various stages of sleep. According to these authors, snoring was found "very rarely" during rapid eye movement (REM) sleep, while its frequency was greatest during Stages $\mathrm{C}$ and $\mathrm{E}$ (roughly corresponding to Stages 2 and 4).

Berger (1961) has suggested that snoring should occur more frequently during REM sleep, since the tonus of the extrinsic laryngeal muscles decreases during this stage. However, most definitions of snoring discount the significance of laryngeal muscles (Robin, 1968).

The present study attempted to resolve some of these questions by systematically correlating snoring with the various stages of sleep. The Ss for this experiment were eight male volunteers (20-30 years of age) who claimed that they were reliable snorers. Electroencephalogram (EEG), electromyogram (EMG), and electro-oculogram (EOG) were continuously monitored on 3 consecutive nights for six of the Ss and on 2 consecutive nights for the remaining two Ss. These physiological measures were taken with a Narco Bio-systems physiograph (Four-A). In addition, a microphone was positioned adjacent to the sleeping Ss, and snoring was continuously monitored.

The sleep records were scored by two observers

*This paper was sponsored by Peter Mikulka, who takes full editorial responsibility for its contents. according to a standardized system (Rechtschaffen \& Kales, 1968). Records were scored by 1-page epochs of 28 -sec duration. If snoring occurred anytime during an epoch, the entire page was considered a snoring epoch. When snoring occurred, an indication was made on the polygraph record with an event marker.

The data relating sleep stages to snoring are given in Fig. 1. The distribution of sleep stages corresponds closely to data obtained in many other sleep studies: a preponderance of Stage 2 sleep (64.6\%), with $18.3 \%$ of the sleep being REM. As one can see from this figure, most of the snoring also occurred in Stage 2. An analysis of variance comparing the amount of snoring in the various sleep stages was significant at the .01 level $(F=15.12, d f=4,28)$. A Duncan range test indicated that the amount of snoring during Stage 2 was significantly greater than the amount during any of the other stages $(p<.01)$; and the amounts of snoring during the other stages were not significantly different from each other.

Although most snoring definitely seems to occur in Stage 2 sleep, Fig. 1 indicates that the proportion of time spent snoring does not differ for the various stages. An analysis of variance indicated that the tendency to snore was not significantly different for the various stages of sleep $(\mathrm{F}=1.08, \mathrm{df}=4,28, \mathrm{p}>.05)$. The data of Fig. 1 tend to disagree with the findings of both Fischgold \& Schwartz (1961) and Berger (1961), since the tendency to snore during REM sleep is not significantly different from the tendency to snore during the other stages.

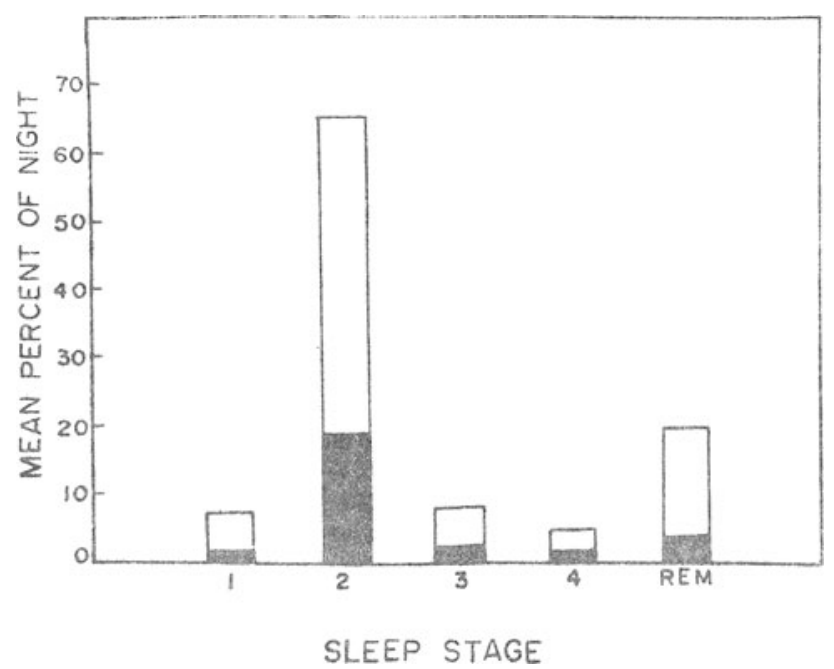

Fig. 1. Mean percentages of the night for the various sleep stages. Shaded areas represent mean snoring percentages, while unshaded areas represent mean nonsnoring percentages. 


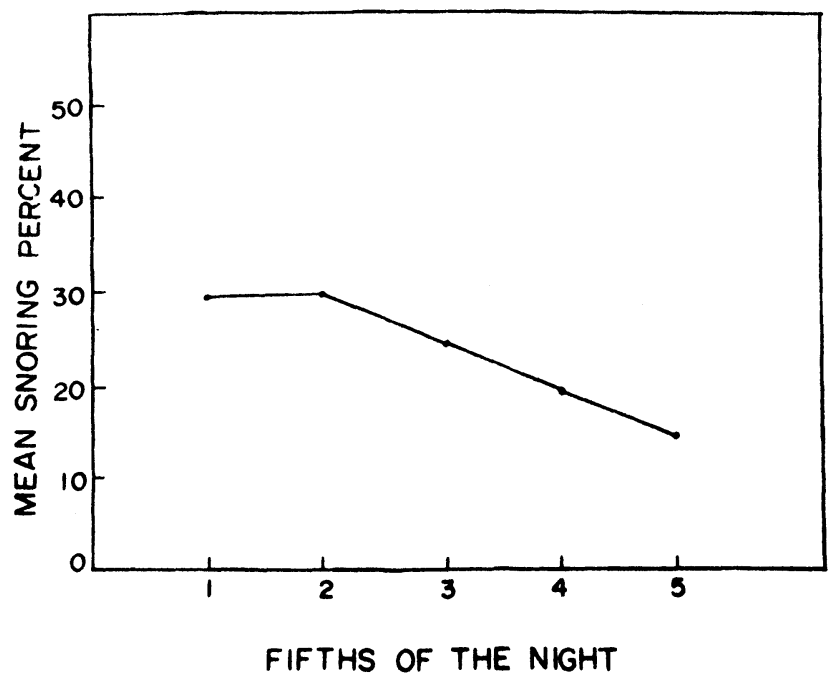

Fig. 2. Mean snoring percentages for fifths of the night.

Figure 2 indicates the temporal distribution of snoring, dividing the night into fifths. It is immediately apparent from this figure that the greatest amount of snoring occurs at the beginning of the night, while the early morning hours have relatively little snoring. An analysis of variance comparing the amounts of snoring for fifths of the night indicated a significant difference $(\mathrm{F}=2.86, \mathrm{df}=4,28, \mathrm{p}<.05)$. A Duncan range statistic yielded significant differences between the last fifth of the night and the first three $(\mathrm{p}<.05)$. This trend has been noted previously (Tsukamoto, 1938) and has been attributed to autonomic changes which widen the nasal passages and reduce the necessity for mouth breathing (Kleitman, 1963).
Although it is well known that sleep on the first recording night is often dissimilar to sleep on subsequent nights (Webb, 1968), differences in amount of snoring between nights were not observed. An analysis of variance comparing amounts of snoring for the three recording nights proved to be not significant $(F=2.43$, $\mathrm{df}=2,12, \mathrm{p}>.05$ ).

The present study has experimentally correlated snoring behavior with the various stages of sleep and with time during the night. It may be interesting to examine the flexibility of these relationships in future studies.
Berger, $\mathbf{R}$. Tonus of extrinsic laryngeal muscles during sleep and dreaming. Science, 1961, 134, 840 .

Boulware, $M$. Sonorous breathing research project findings. New England Journal of Medicine, 1967, 277, 1210-1211.

Fischgold, H., \& Schwartz, B. Snoring during night and day sleep. In G. Wolstenholme and $M$, O'Connor (Eds.), The nature of sleep. Boston: Ciba Foundation Symposium, 1961. Pp. 222-225.

Kleitman, N. Sleep and wakefulness. Chicago: University of Chicago Press, 1963. P. 50.

Rechtschaffen, A., \& Kales, A. A manual of standardized terminology, techniques, and scoring system for sleep stages in human subjects. Washington, D.C: U.S. Government Printing Office, 1968 .

Robin, I. Snoring. Proceedings of the Royal Society of Medicine, $1968,61,575$.

Shapiro, S. On the causes and treatment of snoring. The Eye, Ear, Nose and Throat Monthly, 1971, 50, 77-85.

Tsukamoto, H. Beitrage zur Kenntinis des Schnarchens. Monatschrift fur Ohrenheilk, 1938,72,79.

Webb, W. Sleep: An experimental approuch. New York: Macmillan, 1968. P. 67.

(Received for publication December 15, 1972.) 